\title{
Climates at Minima of the Entropy Exchange Rate
}

\author{
By Akira Noda and Tatsushi Tokioka \\ Meteorological Research Institute, 1-1 Nagamine, Yatabe, Ibaraki 305, Japan \\ (Manuscript received 17 May 1983, in revised form 24 October 1983)
}

\begin{abstract}
An entropy balance equation including radiative heating is developed to examine the principle of minimum entropy exchange hypothesized by Paltridge. It is shown that the thermodynamic dissipation (entropy production) due to latent and sensible heat transport cannot be negligible in the entropy balance model. The zonally averaged two-latitude and ten-latitude models with ten radiative heating levels are used to find climates at minima of the entropy exchange rate. The models are examined under two different conditions of the water vapor distribution: one is the case with a given distribution of absolute humidity and the other the case with a given distribution of relative humidity. Multiple minima are found in the former case, while no minima in the latter case. In the former case, one of the minima corresponds to a climate with distributions of temperature and cloud amount similar to those in the present climate. However, it does not correspond to the least minimum of the entropy exchange rate. It is demonstrated that climates at minimum entropy exchange are very sensitive to the parameterization of the humidity distribution.
\end{abstract}

\section{Introduction}

The atmosphere-ocean-earth system (hereafter called the global system) exchanges energy with the exterior but no material. Such a system is thermodynamically classified as a closed system. The distribution of temperature and heating in the global system is characterized as a heating in the warmer region and a cooling in the colder region. Based on this characteristic of the covariance of temperature and heating fields, the steady-state format of the global climate system has been studied from two different viewpoints: energetics and entropy balance.

Lorenz $(1955,1960)$ gave the following energetical viewpoint on the atmospheric general circulation: The available potential energy $A$ is being generated (with a rate $G$ ) within the atmosphere owing to the horizontally inhomogeneous distribution of diabatic heating and temperature fields, and $A$ is being converted into kinetic energy $K$ (with a rate $C$ ), and $K$ is being dissipated by frictional dissipation (with a rate $D)$. On the long term, the net change in $A$ and $K$ can be regarded as zero aside from possible climatic fluctuations, so that $G=C=D$. Lorenz (1960) speculated that the available potential energy might be generated at the maximum possible rate that can take place in the atmosphere with the existing distribution of incoming solar radiation, and so should the kinetic energy be dissipated.

On the other hand, from the viewpoint of the entropy balance, the entropy $S$ is being supplied through "the entropy exchange process" with the exterior in low latitudes and at the surface, and much more is being extracted in high latitudes and in the atmosphere. There is another process which contributes to the entropy change, i.e., the entropy production through irreversible (or dissipative) processes within the system. The sign of the entropy exchange rate is not definite, and can be either negative or positive. On the other hand, the sign of the entropy production rate cannot be negative according to the second law of thermodynamics; strictly speaking, the entropy production rate is positive definite because no observation indicates that the present global system is in the state of thermodynamic equilibrium owing to the covariance of temperature and heating fields. On the long term, the net entropy change can be regarded as zero, that is, the rates of entropy production and exchange are in balance; this 
implies that the net exchange rate should be negative.

In this respect, Dutton (1973) introduced the entropic energy $N=T_{0}\left(S_{0}-S\right)$ as a measure of the intensity of the atmospheric motion, where $S$ is the entropy of any natural state of the atmosphere, $S_{0}$ the entropy of its assocaited equilibrium state or maximum entropy state, and $T_{0}$ the equilibrium temperature. This state is the motionless, hydrostatic and isothermal one toward which an atmosphere in isolation will naturally tend. He showed that the departure from the equilibrium state is an important factor in considering the origin and maintenance of atmospheric motion. Furthermore, non-equilibrium thermodynamics (e.g., Nicolis and Prigogine, 1977) attributes it to the nature of nonequilibrium (and nonlinearity) that we can observe ordered structures within the system, i.e., the general circulation, for example.

The above viewpoints both suggest that dissipation may play an important role to determine the structure of the general circulation. Recently, Schulman (1977) examined Lorenz's hypothesis of the maximum generation of the available potential energy with the use of a zonally averaged two-dimensional model, and obtained a thermal structure of the atmosphere similar to the observed one. On the other hand, Paltridge $(1975,1978)$, emphasizing strong nonlinearity of the general circulation, hypothesized that the principle of minimum entropy exchange determines the format of global climate. He developed a one-dimensional model of the global system in the meridional direction (Paltridge, 1975). Later, he extended his model to a horizontal two-dimensional one (Paltridge, 1978). $\mathrm{He}$ showed that the distributions of temperature, cloud cover and meridional energy flux determined under the principle are very similar to the observed ones. These two approaches are closely related in the sense that they assume that the dissipation of the general circulation should be maximized (Paltridge, 1978), but are not identical because the thermodynamic dissipation, i.e., the entropy production, contains contributions due to latent and sensible heat transport as well as due to frictional dissipation (see Section 2).

Other climatic studies based on the entropy balance (Golitsyn and Mokhov, 1978; Nicolis and Nicolis, 1980; Grassl, 1981) neglected the thermodynamic dissipation due to the vertical heat transport since they used climate models of the Budyko-Sellers type (Budyko, 1969; Sel- lers, 1969). Moreover, the vertically averaged models produce ambiguity in temperature (Paltridge, 1976, 1978, 1981; Rodgers, 1976), because such models entirely ignore the vertical difference of the atmospheric temperature which is comparable to the horizontal one in the troposphere. We do not know a priori whether or not it is appropriate to use vertically averaged models for the study of the format of earth's climate. Paltridge (1981) extended his model to the vertical direction by defining different temperatures between the surface and the atmosphere and concluded that inclusion of the vertical fluxes (and associated dissipation) does not work. However, this conclusion need be checked because the vertical fields are still roughly parametrized in his model.

Several theoretical studies (Paltridge, 1979, 1981; Sawada, 1981; Mobbs, 1982) have recently reported that the principle of maximum dissipation may hold in nonlinear and non-equilibrium systems. Although such theoretical approaches may be a promising way to examine the validity of the principle, they have been restricted in rather simple systems so far.

The purpose of this paper is to develop an entropy balance equation for the global system, and to investigate numerically the types of climates allowed under the hypothesis of minimum entropy exchange. We develop a zonally averaged model which explicitly takes into account the vertical extent of the atmosphere as well as the meridional one. The entropy balance equation is presented in Section 2 and in the Appendix A, where a special attention is paid in dealing with radiative heating. The entropy exchange rates are also calculated with the use of the data given by Newell et al. (1974) and Dopplick (1979). The zonally averaged model is described in Section 3. The tropospheric part of the model is essentially the same as that used by Schulman (1977), although we take oceanic heat transport into consideration following Paltridge (1975). In Section 4, we find climates at minima of the entropy exchange rate for the model described in Section 3. In section 5 , a similar search is repeated for other models with different parameterizations of heating. In Section 6 , we summarize the main results. The scheme adopted for minimizing is shown in the Appendix B, since it is slightly different from the gradient method developed by Schulman (1977). 


\section{The entropy balance equation}

According to non-equilibrium thermodynamics (e.g., de Groot and Mazur, 1969; Prigogine, 1967), the time derivative of the total entropy $S$ of a system with a volume $\mathrm{V}$ may be written as the sum of two terms

$$
d S / d t=d_{e} S / d t+d_{i} S / d t
$$

where $d_{e} S / d t$ is the rate of entropy exchange due to interactions with the exterior, and $d_{i} S / d t$ is the rate of entropy production due to irreversible processes inside the system.

Let us consider the entropy balance for the global system, which consists of several components, for example, soil, dry air, sea water, sea ice, water vapor, cloud, etc., and in which some of them are changing into one another. Therefore, in general, we can regard the global system as a system consisting of $n$ components amongst which $r$ chemical reactions are possible. As for the chemical reactions, we shall consider phase changes among the water components only and neglect the photo-chemical reaction in the stratosphere for simplicity.

The explicit form of (1) can be given by integrating the entropy equation over the global system:

$$
\begin{aligned}
\frac{\partial}{\partial t} \rho s= & -\operatorname{div}\left(\rho s \boldsymbol{v}+\frac{\boldsymbol{F}_{H}-\sum_{k=1}^{n} \mu_{k} \boldsymbol{F}_{k}}{T}\right) \\
& -\frac{\operatorname{div}\left(\boldsymbol{F}_{s}+\boldsymbol{F}_{l}\right)}{T}+\boldsymbol{F}_{H} \cdot \operatorname{grad} \frac{1}{T} \\
& -\frac{1}{T} P: \operatorname{Grad} \boldsymbol{v}+\frac{1}{T} \sum_{k=1}^{n} \boldsymbol{F}_{k} \cdot \boldsymbol{f}_{k} \\
& -\frac{1}{T}\left(\sum_{k=1}^{n} T \boldsymbol{F}_{k} \cdot \operatorname{grad} \frac{\mu_{k}}{T}\right. \\
& \left.+\sum_{k=1}^{n} \sum_{j=1}^{r} \nu_{k j} \mu_{k} J_{j}\right)
\end{aligned}
$$

where

$$
\boldsymbol{P}: \operatorname{Grad} \boldsymbol{v}=\sum_{m, n} \boldsymbol{P}_{m n} \frac{\partial v_{m}}{\partial x_{n}}=\sum_{m, n} \boldsymbol{P}_{n m} \frac{\partial v_{m}}{\partial x_{n}} .
$$

A derivation of (2) is given in the Appendix A. Notations used are as follows;

$k$ : component;

$\rho_{k}:$ density of $k$;

$\rho:$ total density $\left(=\sum_{k} \rho_{k}\right)$;

$\boldsymbol{v}_{k}:$ velocity of $k$;

$\boldsymbol{v}:$ barycentric velocity $\left(=\sum_{k} \rho_{k} \boldsymbol{v}_{k} / \rho\right)$;

$j$ : chemical reactions of $\mathrm{H}_{2} \mathrm{O} \quad(j=1$ for phase change between gas and liquid states, $j=2$ between gas and solid states, and $j=3$ between liquid and solid states); $J_{j}$ : chemical reaction rate of the reaction $j$; $\nu_{k j}$ : coefficient $\left(\nu_{k j}=-1\right.$ if $k$ appears in the left hand side of the reaction $j, \nu_{k j}=1$ if $k$ appears in the right hand side) (e.g., $\nu_{k 1}=-1, \nu_{k^{\prime}}=1$ for $\mathrm{H}_{2} \mathrm{O}$ (gas) $\rightarrow$ $\mathrm{H}_{2} \mathrm{O}$ (liquid), $k=$ water vapor, $k^{\prime}=$ liquid water);

$s_{k}$ : specific entropy of $k$;

$s:$ specific entropy $\left(=\sum_{k} s_{k} \rho_{k} / \rho\right) ;$

$\boldsymbol{f}_{k}$ : external force;

$\boldsymbol{P}$ : total pressure tensor $\left(\boldsymbol{P}_{m n}=p \delta_{m n}+\tau_{m n}\right.$, $\delta_{m n}=1$ if $m=n, \delta_{m n}=0$, if $\left.m \neq n\right)$

$\tau$ : stress tensor;

$p_{k}:$ partial pressure of $k$;

$p:$ total scalar pressure $\left(=\sum_{k} p_{k}\right)$;

$\boldsymbol{F}_{k}$ : diffusion flow of $k\left(=\rho_{k}\left(\boldsymbol{v}_{k}-\boldsymbol{v}\right)\right)$;

$\boldsymbol{F}_{H}:$ sensible heat flux;

$\boldsymbol{F}_{s}$ : shortwave heat flux;

$F_{l}:$ longwave heat flux;

$\mu_{k}$ : chemical potential.

We thus obtain, with the help of Gauss's theorem,

$$
\begin{aligned}
d_{e} S / d t= & -\int \operatorname{div}\left(\rho s \boldsymbol{V}+\frac{\boldsymbol{F}_{H}-\sum_{k} \mu_{k} \boldsymbol{F}_{k}}{T}\right) d V \\
& -\int \frac{\operatorname{div}\left(\boldsymbol{F}_{s}+\boldsymbol{F}_{l}\right)}{T} d V \\
= & \int_{\sigma}\left(\rho s \boldsymbol{V}+\frac{\boldsymbol{F}_{H}-\sum_{k} \mu_{k} \boldsymbol{F}_{k}}{T}\right) \cdot d \sigma \\
& +\int_{\rho} \rho \frac{Q_{s}+Q_{l}}{T} d V \\
d_{i} S / d t= & \int_{H} \cdot \operatorname{grad} \frac{1}{T} d V+\int \frac{1}{T} \rho \delta d V \\
& +\int_{T} \frac{1}{T} \sum_{k} \boldsymbol{F}_{k} \cdot \boldsymbol{f}_{k} d V \\
& -\int_{\frac{1}{T}}\left(\sum_{k} T \boldsymbol{F}_{k} \cdot \operatorname{grad} \frac{\mu_{k}}{T}\right. \\
& \left.+\sum_{k, j} \nu_{k j} \mu_{k} J_{j}\right) d V
\end{aligned}
$$

where $Q_{s}\left(Q_{l}\right)$ is the heating rate per unit mass due to shortwave (longwave) radiation, $\rho Q_{s}$ $=-\operatorname{div} \quad \boldsymbol{F}_{s}, \quad\left(\rho Q_{l}=-\operatorname{div} \quad \boldsymbol{F}_{l}\right), \quad \delta(=(-1 / \rho) P:$ Grad $v$ ) the heating rate per unit mass due to dissipation of kinetic energy, and $\sigma$ the surface of $V$.

A few remarks are in order about our formulations (3) and (4). First, it should be noted 
that all the contributions due to the radiative heating are contained in (3). Glassl (1981) discussed that the radiative flux should be treated in the same way as $\boldsymbol{F}_{H}$ since the radiative heating is also expressible as the divergence of the flux. However, there is an important difference between $\boldsymbol{F}_{H}$ and the radiative heat flux: The former is transferred through fluid motions and/ or microscopic collisions among material particles, while the latter is transferred via photons. The material particles are in the local equilibrium state, so that they can be characterized by the local temperature. On the other hand, since the photons propagate in the atmosphere with an information of the temperature where they are emitted as blackbody radiation, they are far from the local equilibrium state, so that we cannot assume the Gibbs relation (A4) if the global system is regarded as a photonmaterial system. Therefore, even if the radiative heating occurs inside a material volume, its contribution to the total entropy change must be entirely retained within the term of the entropy exchange rate.

Secondly, it is mentioned that (4) contains a production term related to the latent and sensible heat transport as well as a term due to the frictional dissipation. Let us estimate an order of magnitude of each term on the right hand side of (4) for a vertical column with a unit cross section. We obtain $0.2 \times 10^{-2} \mathrm{~W} / \mathrm{m}^{2} /$ $\mathrm{K}$ for the first term, and $1 \times 10^{-2} \mathrm{~W} / \mathrm{m}^{2} / \mathrm{K}$ for the second term when the following values are adopted: the depth of the planetary boundary layer $\sim 1 \mathrm{~km}$, the mean temperature of it $\sim 270$ $\mathrm{K}$, the lapse rate $\sim 6.5 \mathrm{~K} / \mathrm{km},\left|\boldsymbol{F}_{H}\right| \sim 20 \mathrm{~W} / \mathrm{m}^{2}$, the tropospheric height $H_{t} \sim 10 \mathrm{~km}$, the difference of temperature between the tropopause and the surface $\Delta T \sim 60^{\circ} \mathrm{C}$, and $\rho \delta H_{t} \sim 3 \mathrm{~W} / \mathrm{m}^{2}$ (Newell et al., 1974). The third term vanishes if the external forces $\boldsymbol{f}_{k}$ are independent of $k$, because $\sum_{k} F_{k}=0$. This is the case for the global system since $\boldsymbol{f}_{k}$ express the gravitational force. The 'fourth term comes from $-\sum_{k} \mu_{k} d c_{k} / d t$ in (A3), which vanishes if the phase changes occur under the locally saturated condition because the chemical potentials then take the same value and $\sum_{k} d c_{k} / d t=0$ holds by the mass conservation. Such a condition may be approximately fulfilled in the clouds, but is not in the unsaturated atmosphere. Let us estimate the entropy production rate through the phase change at the sea surface with the use of the relation (Iribarne and Godson, 1973)

$$
\mu_{w}-\mu_{v}=R T \ln p_{v s} / p_{v}=-R T \ln h,
$$

where $w$ and $v$ stand for liquid water and vapor, respectively, $p_{v s}$ the saturation pressure of water vapor, $h\left(=p_{v} / p_{v s}\right)$ the relative humidity, and $R=4.6 \times 10^{2} \mathrm{~J} / \mathrm{kg} / \mathrm{K}$ for water vapor. If we take $3 \mathrm{~mm} /$ day (i.e., $3.5 \times 10^{-5} \mathrm{~kg} / \mathrm{m}^{2} / \mathrm{sec}$ ) for the evaporation rate and $h=0.8$, we obtain $0.4 \times 10^{-2} \mathrm{~W} / \mathrm{m}^{2} / \mathrm{K}$. Thus, since the latent and sensible heat terms are not negligible, the principle of maximum dissipation of kinetic energy by Lorenz (1960) is, contrary to the discussion by Paltridge (1978), not necessarily equivalent to the principle of maximum entropy production.

Finally, noting that the normal components of $v, F_{H}$ and $\boldsymbol{F}_{k}$ vanish at the boundaries of the global system, we can calculate the entropy exchange rate (3) only from the radiative heating without knowing the distribution of other diabatic heatings within the system. Fig. 1 shows latitudinal distributions of the zonally averaged entropy exchange rate (solid line), and of its components in the atmosphere (dash dotted line) and in the ground (dash double dotted line) calculated from the data given by Newell et al. (1974) and Dopplick (1979). The entropy exchange rate and its components are of the order of $10^{-1} \mathrm{~W} / \mathrm{m}^{2} / \mathrm{K}$ at each latitude. After being

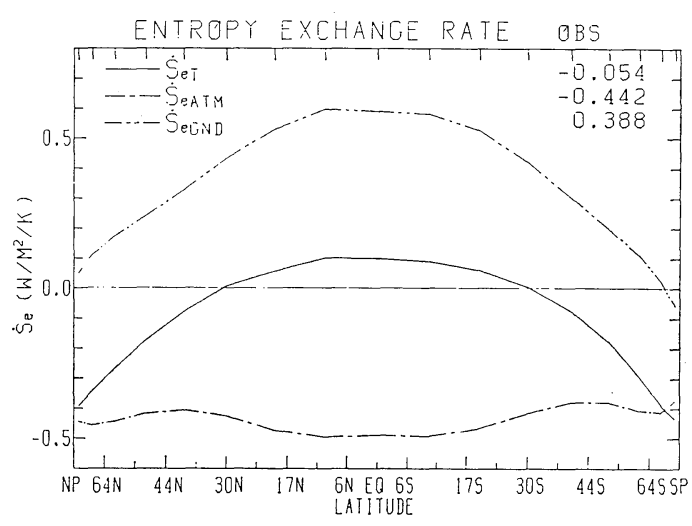

Fig. 1 The entropy exchange rate calculated from the observed data given by Newell et al. (1974) and Dopplick (1979). $\dot{S}_{e A T M}$ and $\dot{S}_{e G N D}$ are the atmospheric and ground entropy exchange rates, and correspond to the first and second terms on the right side of (6), respectively. $\dot{S}_{e T}$ is the total entropy exchange rate $\left(\dot{S}_{e A T M}+\dot{S}_{e G N D}\right)$. Globally averaged values of them are given on the right upper side. 
Table 1 Seasonal variation of the entropy exchange rate.

\begin{tabular}{lccc}
\hline & \multicolumn{3}{c}{ Entropy Exchange Rate $\left(\mathrm{W} / \mathrm{m}^{2} / \mathrm{K}\right)$} \\
& Atmosphere & Ground & $\begin{array}{l}\text { Global } \\
\text { Mean }\end{array}$ \\
\hline Dec.-Feb. & -0.432 & 0.383 & -0.049 \\
Mar.-May & -0.440 & 0.396 & -0.044 \\
Jun.-Aug. & -0.455 & 0.387 & -0.068 \\
Sept.-Nov. & -0.440 & 0.384 & -0.056 \\
Annual Mean & -0.442 & 0.388 & -0.054 \\
\hline
\end{tabular}

integrated globally, the total entropy exchange rate is expected to have a negative value. Indeed, as can be seen in Table 1, its seasonal and annual mean values become negative definite. Moreover, further calculations, which have been done for the convenience of a later comparison in Section 4, indicates that the entropy exchange rate of the global system below $100 \mathrm{mb}$ is $-5.0 \times 10^{-2} \mathrm{~W} / \mathrm{m}^{2} / \mathrm{K}$ and that for the annual mean temperature and heating fields is $-5.2 \times 10^{-2} \mathrm{~W} / \mathrm{m}^{2} / \mathrm{K}$. They are of the order of $10^{-2} \mathrm{~W} / \mathrm{m}^{2} / \mathrm{K}$. This agrees with the order of magnitude of the entropy production rate estimated in the previous paragraph, suggesting that the entropy production rate and exchange rate of the present climate are in balance. Hereafter, we assume that

$$
d_{e} S / d t=-d_{i} S / d t \text {. }
$$

Therefore, we identify maximum entropy production with minimum entropy exchange as was done by Paltridge (1975, 1978).

\section{The zonally averaged model}

Our climate model is basically similar to that of Schulman (1977). The global system is divided into $N$ latitude zones with the same area. The main differences are as follows: i) The entropy exchange rate is extremized. ii) The vertical profile of a temperature field $T(z, \varphi)$ at a latitude $\varphi$ is represented by a surface temperature $T_{s}(\varphi)$ and a lapse rate $\Gamma(\varphi)$, i.e., $T(z, \varphi)=$ $T_{s}(\varphi)-\Gamma(\varphi) z$, where $z$ is the altitude. iii) Clouds are explicitly treated in the radiative heating scheme. iv) The ocean is included after Paltridge (1975). v) The surface flux of latent heat is computed in a conventional way to avoid a large temperature gap between the ground temperature $T_{g}$ and $T_{s}$. The details are described below.

a) The zonally averaged entropy exchange rate and boundary conditions
Assuming zonal uniformity, we obtain the entropy exchange rate $\dot{S}_{e}$ per unit area from (3):

$$
\begin{aligned}
\dot{S}_{e}= & \frac{1}{2 g} \int_{-1}^{1} d x \int_{0}^{p_{s}} d p \frac{Q_{s}+Q_{l}}{T} \\
& +\frac{1}{2} \int_{-1}^{1} d x \int_{-h_{s}}^{0} \rho \frac{Q_{s}+Q_{l}}{T_{g}} d z
\end{aligned}
$$

where $g$ is the acceleration of gravity, $x=\sin \varphi$, $p_{s}$ the surface pressure $(=1000 \mathrm{mb}), h_{s}$ the depth of the surface layer influenced by the radiative heating.

Since the global system gains no net heating, the boundary conditions become

$$
H=\frac{1}{2} \int_{-1}^{1} d x\left(F_{s}+F_{l}\right)=0
$$

at the top of the atmosphere, and

$$
F_{s}=F_{l}=F_{L E+H}=0,
$$

at $z=-h_{s}$, where $F_{s}$ and $F_{l}$ are the net upward fluxes of the shortwave and the longwave radiation, respectively, and $F_{L E+H}$ the upward latent plus sensible heat flux. Energy balance of the surface layer, i.e., $-h_{s} \leqq z \leqq 0$, within a latitude zone requires that (Paltridge, 1975)

$$
F_{s}+F_{l}+F_{\text {ocn }}+F_{L E+H}=0,
$$

at $z=0$. Here $F_{\text {ocn }}$ is the net meridional oceanic energy flow into the zone, i.e., $F_{\text {ocn }}(i)=F_{\text {ocn }}{ }^{M}(i)$ $-F_{\text {ocn }}{ }^{M}(i-1)$, where $i(1 \leqq i \leqq N)$ is the zone number increasing northward, and $F_{\text {ocn }}{ }^{M}(i)$ the northward meridional oceanic energy flow at the northern boundary of the $i$-th zone so that $F_{\text {ocn }}{ }^{M}(0)=F_{\text {ocn }}{ }^{M}(N)=0$.

b) Radiative, latent and sensible hearting schemes

We use the parameterization schemes of Lacis and Hansen (1974) for the shortwave radiation and of Katayama (1974) for the longwave radiation. Both schemes are slightly modified from the original ones so that parameterized absorption functions may be continuous. Our model includes absorptions due to $\mathrm{H}_{2} \mathrm{O}$ and $\mathrm{CO}_{2}$ only, and neglects ozone absorption. A fixed mixing ratio $\left(4.89 \times 10^{-4} \mathrm{~g} / \mathrm{g}\right)$ is assumed for $\mathrm{CO}_{2}$. We adopt two types of water vapor distributions: one with a given distribution of absolute humidity where the observed data from Oort and Rasmusson (1971) are used assuming the symmetric distribution in both hemispheres, and the other with a given distribution of relative humidity following Manabe and Wetherald (1967).

The radiative fluxes are calculated for each 
$100 \mathrm{mb}$ interval from 0 to $1000 \mathrm{mb}$. Three types of clouds are considered in the model, i.e., high, middle and low clouds. We assume that the depth of each cloud is $100 \mathrm{mb}$ and that clouds are randomly overlapped. The cloud bases are determined with the same procedure as proposed by Katayama (1966). We use $p_{H}, p_{M}, p_{L}$ and $p_{s}$ to indicate the pressures at the bases of high, middle and low clouds, and the surface pressure, respectively. The pressure $p_{H}$ is assumed to be the level where the air temperature is $-40^{\circ} \mathrm{C}$. The other pressures are determined from $p_{L}=\left(5 p_{s}+p_{H}\right) / 6$ and $p_{M}=\left(p_{H}+p_{\mathrm{L}}\right) / 2.5$. However, in order for the cloud bases to agree with the levels where the radiative fluxes are calculated, we adjust the cloud bases to be the lower boundaries of the layers in which $p_{H}, p_{M}$ or $p_{L}$ are contained. If two of them are contained in the same layer, the upper cloud base is set to the upper boundary of the layer. Halfblack emissivity is assumed for the high cloud, and black emissivity for the middle and low clouds, in the longwave radiation scheme. As for the cloud optical thickness $\tau_{c}$ (Lacis and Hansen, 1974), we follow Somerville et al. (1974) and adopt the value 2, 8 and 16 for clouds between 0 to $400 \mathrm{mb}, 400$ to $700 \mathrm{mb}$, and 700 to $1000 \mathrm{mb}$, respectively.

The surface is assumed to be black for the longwave radiation. The ground albedo is specified after Sellers (1965). The downward shortwave flux at the top of the atmosphere is fixed to its annual mean tabulated in the Smithsonian Meteorological Tables (1966), while the equinox condition is used for the mean zenith distance of the sun.

The oceanic meridional energy flux $F_{\text {ocn }}{ }^{M}$ is determined by giving its ratio to the atmospheric meridional energy flux $F_{\text {atm }}{ }^{M}$ after Paltridge (1975). $F_{L E+H}$ is computed with the use of the observed Bowen ratio $B$ (Budyko, 1978) and the bulk aerodynamic formula for the sensible heat flux $F_{H}$ (Schulman, 1977), i.e.,

e. $F_{H}=\rho_{s} C_{D} C_{p} V_{0}\left(T_{g}-T_{s}\right)$,

whence

$$
F_{L E+H}=\left(1+\frac{1}{B}\right) F_{H},
$$

where $\rho_{s}$ is the air density at the surface, $C_{D}$ the surface drag coefficient, $C_{p}$ the specific heat capacity at constant pressure, $V_{0}$ the anemometer height wind speed. In (10) $V_{0}=10 \mathrm{~m} / \mathrm{s}$ is assumed and $C_{I}$ is computed as the mean of $1 \times 10^{-3}$ for the sea and $2 \times 10^{-3}$ for the land, weighted by the appropriate land fraction for each latitude zone. The choice of parameters in $F_{L E+H}$ is not important for the present model since $F_{L E+H}$ is passively determined so as to satisfy the flux balance (9).

\section{c) Minimization scheme}

With the use of the parameterization described above, we can calculate $\dot{S}_{e}$ from (6), if we know $T_{s}(\mathrm{~K}), \Gamma(\mathrm{K} / \mathrm{km})$, and cloud amounts of high, middle and low clouds, $C l_{H}, C l_{M}$ and $C l_{L}(\%)$ at each latitude. Therefore, $\dot{S}_{e}$ is a function of $5 N$ variables for an $N$-latitude model. Following the procedure developed by Schulman (1977), we are to minimize $\dot{S}_{e}$ within the domain

$$
\begin{aligned}
200 & \leqq T \\
0 & \leqq \Gamma \leqq \Gamma_{d} \\
0 & \leqq C l_{H}, C l_{M}, C l_{L} \leqq 100,
\end{aligned}
$$

under the contraints of (7) and (8), where $T$ is the air temperature, and $\Gamma_{d}$ the dry adiabatic lapse rate $\left(g / C_{p}=9.6 \mathrm{~K} / \mathrm{km}\right)$. When a temperature below $200 \mathrm{~K}$ is computed, we replace it with $T=200 \mathrm{~K}$. See the Appendix B for the details of the procedure.

\section{Two-latitude model and ten-latitude model}

\section{a) Two-latitude model}

In order to investigate the general characteristics of climates of the model at minima of $\dot{S}_{e}$, we first develop the two-latitude model in which the hemisphere is divided into two zones with the same area: a low latitude zone $(i=1)$ and a high latitude zone $(i=2)$. Fig. 2 shows the fluxes to be calculated in the two-latitude model.

Before directly searching for the minima of $\dot{S}_{e}$ of the global system we should remark the following property of the minima. Let $\dot{S}_{e}(i)$ and $H_{i}$ be the entropy exchange rate and the net downward radiative flux at the top of the atmosphere in the zone $i$, respectively, whence $\dot{S}_{e}=\sum_{i=1}^{2} \dot{S}_{e}(i) / 2$ and $H=\sum_{i=1}^{2} H_{i} / 2=0 . \quad$ Then, a set of the independent variables which minimize $\dot{S}_{e}$ also minimizes each $\dot{S}_{e}(i)$ under the condition of given $H_{i}$. Since $H_{2}=-H_{1}$ for the two-latitude model, we may regard $H_{1}$ as a parameter in the present model. Therefore, minima of $\dot{S}_{e}(i)$ are searched for a specified value of $H_{1}$. This process is repeated by changing initial fields. This is necessary because the uniqueness of minimum of the functions $\dot{S}_{e}(i)$ is not guaranteed. $H_{1}$ is changed systematically from $0 \mathrm{~W} / \mathrm{m}^{2}$ to 


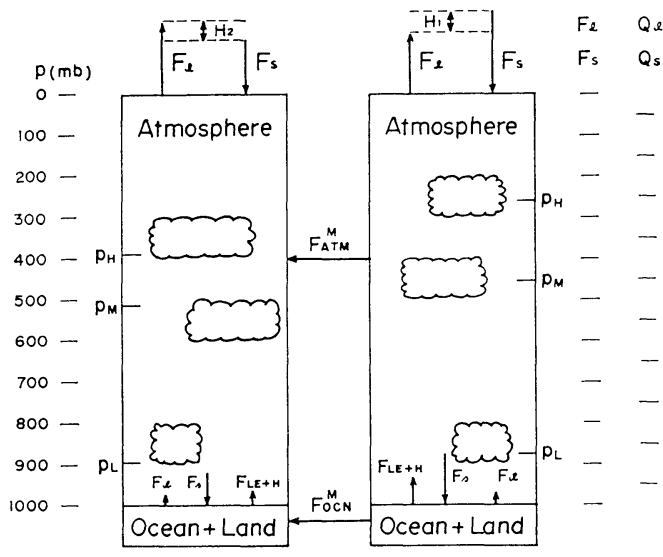

Fig. 2 A schematical presentation of the twolatitude model. The cloud base pressure levels of high, middle and low clouds given by Katayama (1966) are denoted by $p_{H}$, $p_{M}$ and $p_{L}$, respectively. The three types of clouds used in the present radiation scheme are illustrated in the figure. Details are found in the text. The levels at which the radiative flux $F_{s}, F_{l}$ and the radiative heating rate $Q_{s}, Q_{l}$ are calculated are indicated by solid lines on the right side.

$100 \mathrm{~W} / \mathrm{m}^{2}$ at intervals of $10 \mathrm{~W} / \mathrm{m}^{2}$. For each $H_{1}$, we minimize $\dot{S}_{e}(1)$ and $\dot{S}_{e}(2)$, starting from every combination of the following initial values: $\left(T_{s}, \Gamma\right)=(300 \mathrm{~K}, 6.5 \mathrm{~K} / \mathrm{km}),(250 \mathrm{~K}, 4.5 \mathrm{~K} / \mathrm{km})$ and $C l_{H}=C l_{M}=C l_{L}=10,30,50,70$ and $90 \%$. All the minimizing experiment in this section are performed with a fixed distribution of absolute humidity given by Oort and Rasumusson (1971). The other parameters used in the numerical calculation are presented in Table 2 . We have found multiple minima for $\dot{S}_{e}(1)$ and $\dot{S}_{e}(2)$. Variations of the least minimum of $\dot{S_{e}}$ and minimizing values of $T_{s}$ are shown as a function of $H_{1}$ in Fig. 3. Here the entropy exchange rates
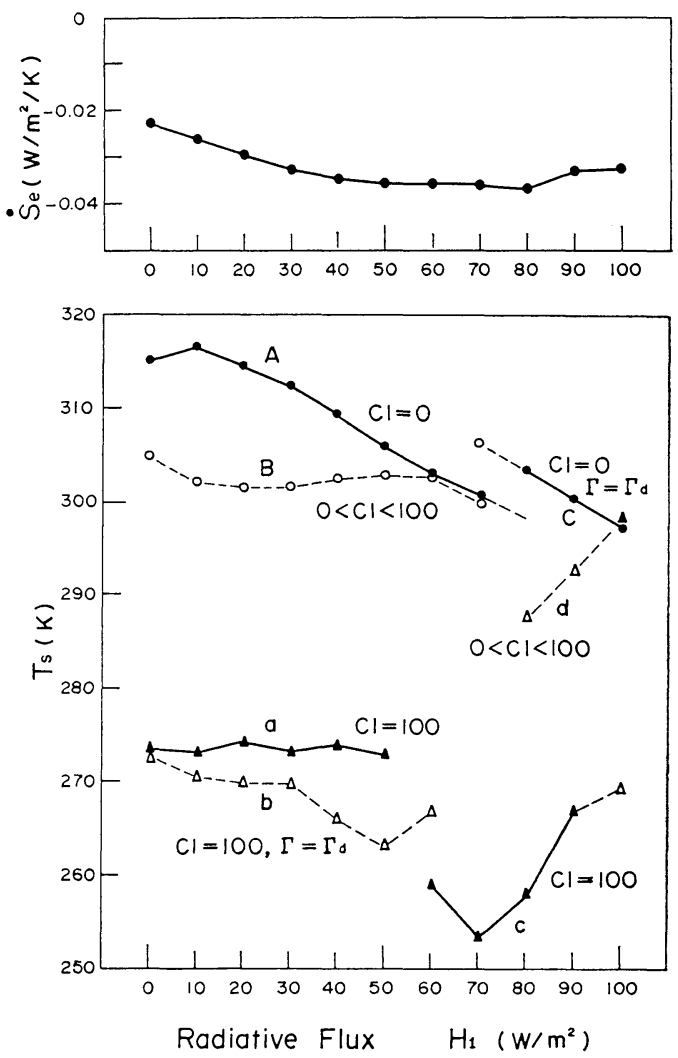

Fig. 3 Variation of the least minimum entropy exchange rate (top) and minimizing surface temperature (bottom) as a function of the net downward radiation flux at the top of the atmosphere for the two-latitude model. Circles and triangles in the lower figure show the minimizing temperature for the low and high latitude zones, respectively. Black ones give the least minimum entropy exchange rate. The total amount of clouds $\mathrm{Cl}$ on each line is as follows:

(A) $\mathrm{Cl}=0$, (B) $0<\mathrm{Cl}<100$, (C) $\mathrm{Cl}=0$ with $\Gamma=\Gamma_{d}$, (a) $\mathrm{Cl}=100$, (b) $\mathrm{Cl}=100$ with $\Gamma=\Gamma_{d}$, (c) $\mathrm{Cl}=100$, and (d) $0<\mathrm{Cl}<100$.

Table 2 Zonally averaged constants used in the two-latitude and the ten-latitude models.

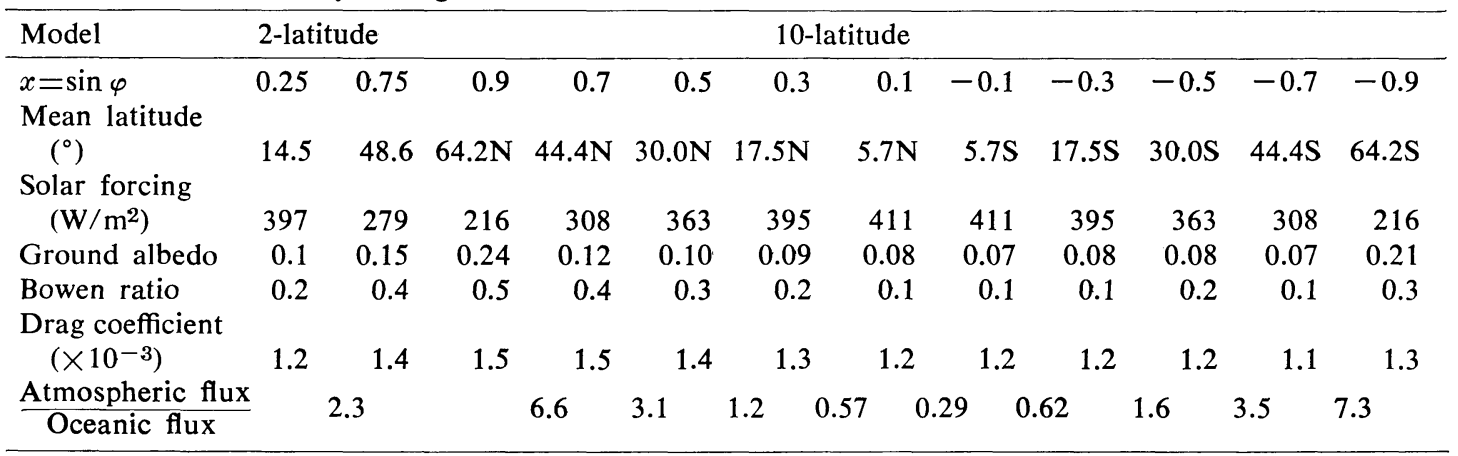


above $100 \mathrm{mb}$ are omitted simply because ozone is neglected in the model.

The minimizing fields have the following characteristics. In the low latitude zone, two types of minimizing fields are found: One is characterized as no clouds, and the other as moderate cloudiness. The cloudiness of the latter field, details of which are not shown here, may contain about 10\% errors, which means that $\dot{S}_{e}(1)$ is not sensitive to some combinations of $C l_{H}, C l_{M}$ and $C l_{L}$. The minimum value of $\dot{S}_{e}(1)$ is smaller for the former field than for the latter. In the high latitude zone, cloudiness becomes $100 \%$ for $\left|H_{2}\right| \leqq 70 \mathrm{~W} / \mathrm{m}^{2}$ although the field $\left(T_{s}, \Gamma\right)$ does not converge uniquely. Another field with moderate cloudiness appears for $\left|H_{2}\right|>70 \mathrm{~W} / \mathrm{m}^{2}$, and attains the least minimum for $\left|H_{2}\right|=100 \mathrm{~W} / \mathrm{m}^{2}$. In summary, a climate similar to the present one is derived as one of the minimizing fields from the principle of minimum entropy exchange rate, although it does not attain the least value.

Here we shortly consider the reason why the principle of minimum entropy exchange has produced such an extreme climate besides a climate similar to the present one. The entropy exchange rate tends to decrease when the temperature in the heating regions (the surface) becomes higher and/or the temperature in the cooling regions (the atmosphere) becomes colder. Clouds play a decisive role in this respect; i.e., an increase of cloudiness enhances cooling due to longwave radiation in the coldest regions above the highest clouds, while it reduces heating due to the shortwave radiation in the hottest regions below the lowest clouds, especially, at the surface. On the other hand, a decrease of cloudiness increases not only the surface heating, but also the surface temperature to satisfy the flux balance (9). Therefore, climates with and without clouds in the whole sky are both plausible from the minimum principle. In the two-latitude model, the heating effect has prevailed in the low latitude zone, and the cooling effect has prevailed in the high latitude zone.

b) Ten-latitude model

We increase the horizontal resolutions of the model and examine if the above results still hold or not. We employ a ten-latitude model for this purpose. Table 2 shows the parameters used in the present ten-latitude model. The tenlatitude model is expected to increase the multiplicity of solutions because the minimizing function becomes more complex. However, we have obtained the same types of minimizing fields as before for the two-latitude model. The stability of the converged states is checked by the following way. We first search for a converging field starting from an arbitrarily specified initial field. Then, we randomly vary the converging $T_{s}$ field within the range of $\pm 5^{\circ} \mathrm{C}$ and repeat the minimizing procedure from the modified field.

First we show the case where the initial field is taken as $C l_{H}=C l_{M}=C l_{L} \approx 0(\%)$ for $x= \pm 0.1$, \pm 0.3 and \pm 0.5 , and $C l_{H}=C l_{M}=C l_{L} \approx 100(\%)$ for $x= \pm 0.7$ and \pm 0.9 . Fig. 4 shows distributions of minimizing temperature and radiative heating fields in the atmosphere. Fig. 5 illustrates the flux balance both at the surface and the top associated with the minimizing fields, while Fig. 6 the latitudinal distributions of the entropy exchange rate and its components. As is expected from the two-latitude model, the climate in this case is characterized as no clouds in low latitudes and 100\% cloudiness in high latitudes, which leads to a large cooling in the

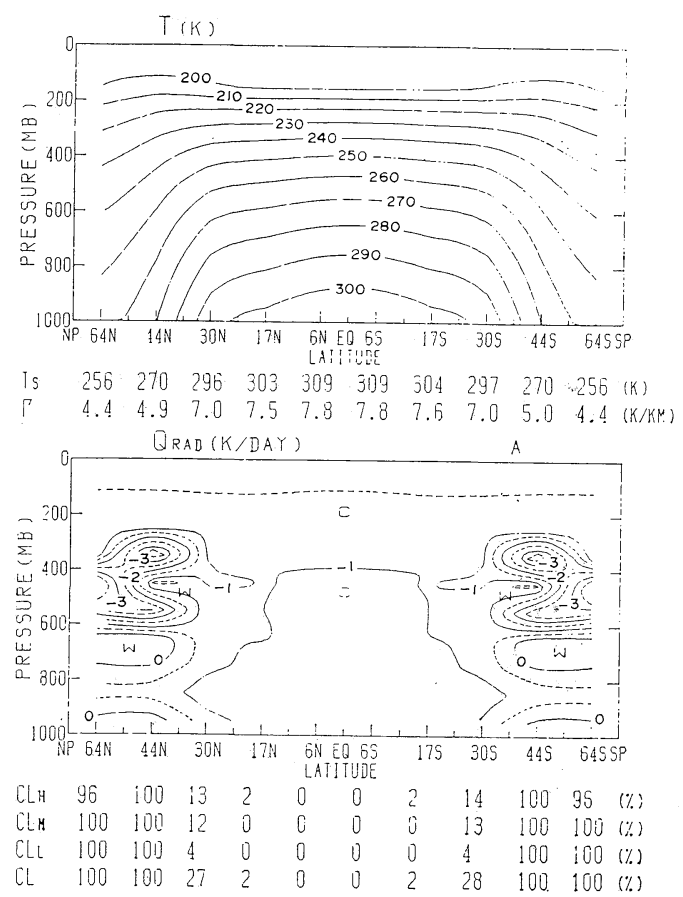

Fig. 4 Minimizing fields of temperature (top) and net radiative heating ( $K /$ day) (bottom) for the ten-latitude model. The surface temperature $\left(T_{s}\right)$, the lapse rate $(\Gamma)$, the cloud amount of high $\left(\mathrm{Cl}_{H}\right)$, middle $\left(\mathrm{Cl}_{\mathrm{M}}\right)$ and low $\left(C l_{L}\right)$ clouds and the total cloud arount $(\mathrm{Cl})$ at each latitude zone are. also listed. 

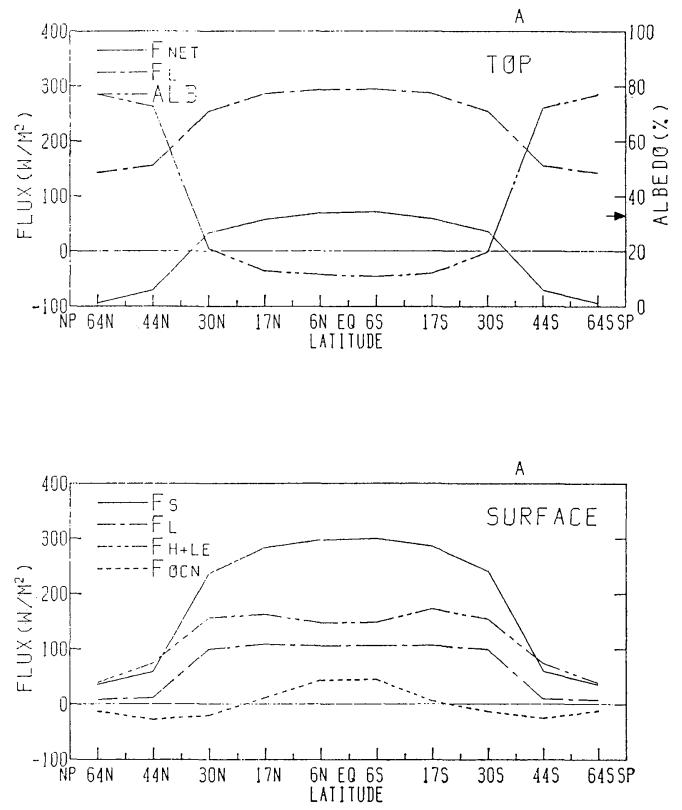

Fig. 5 Flux balance at the top of the atmosphere (top) and at the surface (bottom) associated with the minimizing fields of Fig.4. $F_{\mathrm{NET}}, F_{l}$ and $A L B$ in the upper figure indicate the net downward radiative flux, the upward longwave flux at the top and the planetary albedo. An arrow on the right ordinate is the globally averaged albedo. Positive values of $F_{\text {ocn }}$ indicate heating in the ocean.

polar upper atmosphere and high temperature at the equatorial surface. Another characteristic to be noted is that the minimizing variables are symmetric with respect to the equator in spite of the asymmetric distribution of the parameters shown in Table 2. This characteristic is also found by Paltridge (1975).

Other experiments are performed with initial fields similar to the present climate. One of the converged states is shown in Figs. 7, 8 and 9, which corresponds to Figs. 4, 5 and 6, respectively. Owing to the moderate cloud amounts, the distributions of temperature and heating fields resemble the observed ones fairly well. The minimum value of $\dot{S}_{e},-0.024 \mathrm{~W} / \mathrm{m}^{2} / \mathrm{K}$, is clearly larger than that in the former case, $-0.038 \mathrm{~W} / \mathrm{m}^{2} / \mathrm{K}$. After performing the similar experiments with different initial fields, we have found that the least minimum state in our model is that shown in Figs. 4, 5 and 6.

There is some discrepancy between the calculated $\dot{S}_{e}$ in Fig. 9 and the observed $\dot{S}_{e}$ estimated

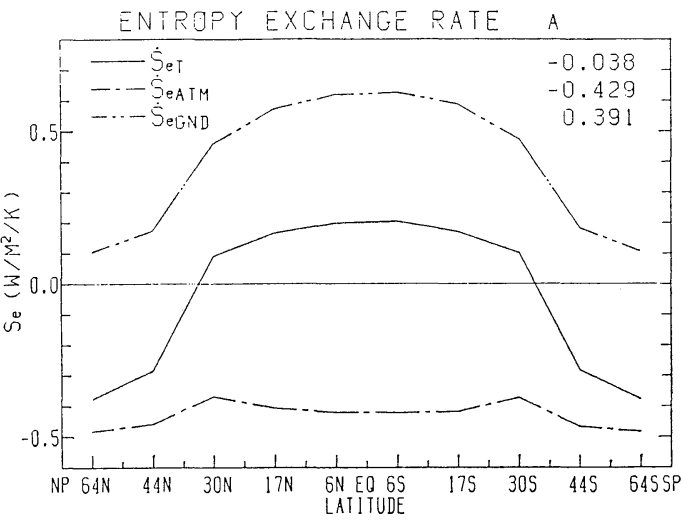

Fig. 6 As in Fig. 1 but for the entropy exchange rate associated with the minimizing fields of Fig. 4. Note that $S_{e A T M}$ is a contribution only from 100 to $1000 \mathrm{mb}$ of the model atmosphere.

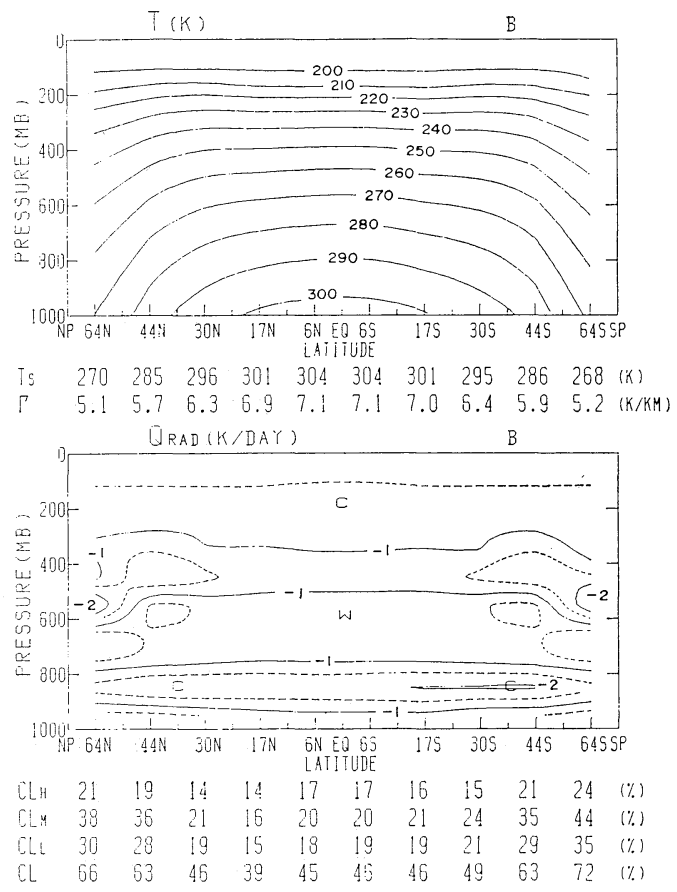

Fig. 7 As in Fig. 4 but for another minimizing fields which resemble the present climate.

in Section 2 in spite of the similar distributions of temperature, cloudiness and humidity. One of the reasons may be ascribed to the inaccurate treatment of the stratosphere in the model. In fact, the relation $T=\max \left(T_{s}-\Gamma z, 200\right)$ practically always assigns $200 \mathrm{~K}$ to the stratosphere above $100 \mathrm{mb}$ throughout the minimizing ex- 

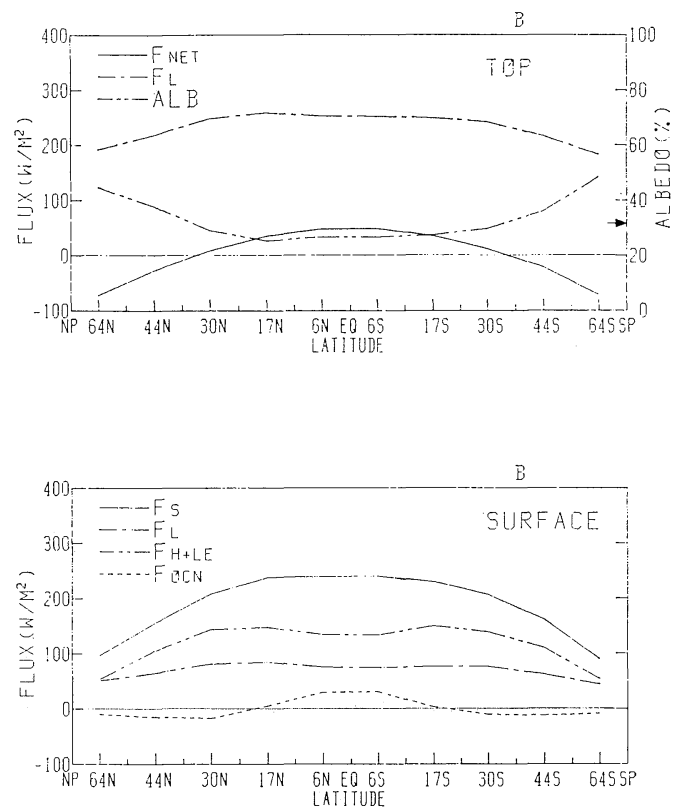

Fig. 8 As in Fig. 5 but for flux balance associated with the minimizing fields of Fig. 7 .

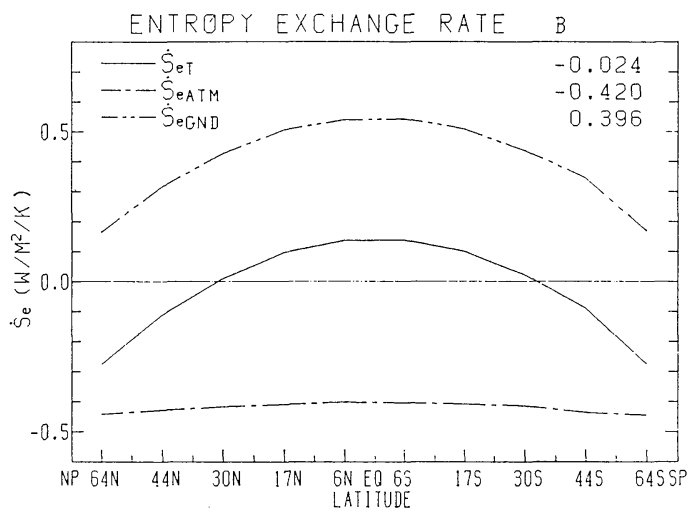

Fig. 9 As in Fig. 6 but for the entropy exchange rate associated with the minimizing fields of Fig. 7.

periment. Therefore, the atmosphere is cooled there by $0.9 \mathrm{~K} /$ day at every latitude, which in turn reduces $\dot{S}_{e}$ by about $5 \times 10^{-2} \mathrm{~W} / \mathrm{m}^{2} / \mathrm{K}$. This suggests that we should accurately compute the stratospheric radiative heating to compare $\dot{S}_{e}$ with the observed value. Nevertheless, because the radiative equilibrium condition is better realized in the stratosphere than in the troposphere, the tropospheric climates obtained above may not be altered essentially even if the stratosphere is more realistically treated in the model.

\section{Models with different heating schemes}

a) Thick clouds with fixed cloud bases

Since cloud bases have not been fixed in the model discussed in the preceding sections, we cannot regard $\dot{S}_{e}$ as a continuous function. However, fixing the cloud bases in the same model used in the preceding sections, we have checked that such discontinuities do not affect the results qualitatively. Next, let us examine the effect of cloud thickness.

Choosing the cloud thickness of high, middle and low clouds as $200 \mathrm{mb}$, and fixing the cloud base levels at 400,600 and $800 \mathrm{mb}$, we have repeated the same procedure as described in Section 4. Consequently, we have obtained three kinds of climates: Two of them are similar to those obtained in Section 4. The third mode is characterized as $100 \%$ cloudiness at every latitude, and attains the least minimum of $\dot{S}_{e}$. Fig. 10 shows a minimizing field of the new kind for the ten-latitude model. In virtue of a very high temperature at the lower levels in the low latitudes, a large contrast of the entropy exchange rate is expected between the lower and higher levels.
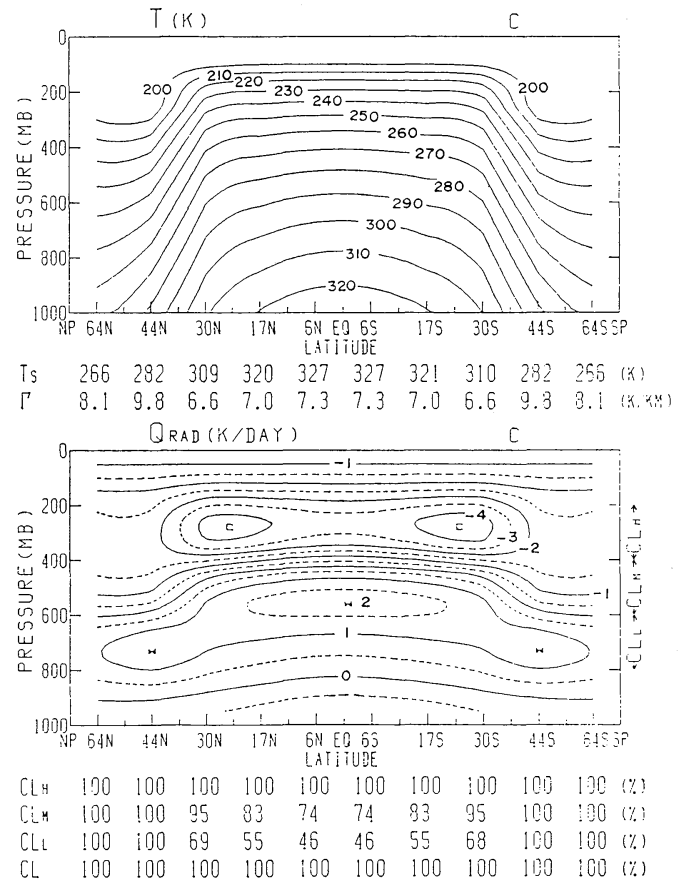

Fig. 10 As in Fig. 4 but for the ten-latitude model with fixed cloud bases and $200 \mathrm{mb}$ cloud thickness. 
b) Prescribed relative humidity

The absolute humidity has so far been prescribed. Therefore, only the cloudiness has been responsible for changing formats of the flux balances at the boundaries. Here we prescribe the relative humidity instead of the absolute humidity following Manabe and Wetherald (1967), i.e., the relative humidity decreases linearly from $77 \%$ at the earth's surface to a constant stratospheric mixing ratio $\left(2.5 \times 10^{-6}\right.$ $\mathrm{kg} / \mathrm{kg}$ of air). Under this condition, however, all the minimization experiments have lead to unreasonable ranges of $T_{s}$. One of the remarkable features common to the present experiments is a very large increase of the surface temperature in low latitudes due to the enhanced greenhouse effect. However, such an extreme greenhouse effect seems to have been excluded $a$ priori both in Schulman's model (Schulman, 1977) and in Paltridge's model (Paltridge, 1975, 1978). In the former model, clouds are not explicitly treated but are parameterized in terms of the prescribed albedo and relative humidity so that, for the highly cloudy atmosphere, the vertical profile of the radiative heating field is quite different from the one calculated by the radiative heating scheme with explicit clouds. On the other hand, in the latter model, the humidity parameterization, which is implicitly incorporated into the longwave parameterization, is based on the present climate.

c) Infrared continuum absorption by water vapor

Katayama's longwave radiation scheme does not consider the infrared continuum absorption by water vapor in the $8-12 \mu \mathrm{m}$ region of the spectrum. However, it is known that the absorption in this region gives a large cooling rate near the surface in the low latitudes when there are no clouds. This is due to the dependence of the absorption coefficient on the water vapor partial pressure (e.g., Roberts et al., 1976; Hunt and Mattingly, 1976). This absorption might affect $\dot{S}_{e}$ of the models with the prescribed relative humidity, because the cooling rate increases in hotter regions. However, this does not alter the situations very much from the following reason. Cooling by the water vapor continuum absorption in the clear atmosphere is mainly due to the divergence of the downward radiative fluxes, which in turn heats the surface. Since the cooling region is restricted near the surface, the temperature of the cooling region and that of the heating region are not different very much. Therefore, the effect of the absorption in the water vapor continuum on $\dot{S}_{e}$ is expected to be small. Indeed, minimizing experiments similar to those described so far but with the water vapor continuum absorption have not been able to find minima as before for the models with the prescribed relative humidity.

\section{Conclusions}

We have developed an entropy balance equation including radiative heating to examine the principle of minimum entropy exchange hypothesized by Paltridge $(1975,1978)$. Based on the equation, we have shown that the thermodynamic dissipation, i.e., entropy production, due to the latent and sensible heat transport, cannot be neglected in the entropy balance equation. Therefore, contrary to the discussion by Paltridge (1978), the principle of maximum dissipation of kinetic energy in the energy cycle (Lorenz, 1960) is not necessarily equivalent to the principle of maximum entropy production.

Using the zonally averaged two-latitude and ten-latitude models, we have obtained multiple minima of the entropy exchange rate for the model with a given distribution of absolute humidity. Two types of climates are possible in low latitudes: no clouds in one case, and moderate cloudiness in the other. The former attains the least minimum.

We have not been able to find minima for the models with a given distribution of relative humidity owing to the extreme greenhouse effect. This effect was possibly precluded in the previous studies (Schulman, 1977; Paltridge, 1975, 1978) because of the parameterizations used in the models. The inclusion of the watre vapor continuum effect into the model does not qualitatively change the above results much.

Thus, it is clarified by the present study that climates at minimum entropy exchange are very sensitive to the parameterization of a distribution of humidity. So it seems to be a rather subtle assertion that the present climate is at the least minimum of the entropy exchange rate. Although we have no intention of saying that the principle of minimum entropy exchange is questionable, we can at least say that simple thermodynamic models are inadequate to examine the validity of the principle.

\section{Acknowledgments}

The authors wish to thank Dr. A. Katayama 
for teaching them the details of his radiation scheme. Thanks are also due to Drs. G. W. Paltridge, L. L. Schulman and anonymous referees for valuable comments on the manuscript. Dr. T. G. Dopplick kindly sent them the grid point data of the radiative heating. Computations were made on the HITAC $\mathrm{M}-200 \mathrm{H}$ Computer of the Meteorological Research Institute.

\section{Appendix A}

\section{A derivation of entropy balance equation}

The entropy balance equation is derived from conservation of mass (A1), the internal energy equation (A2) and the Gibbs relation applied to a mass element or parcel (A3):

$$
\begin{aligned}
& \frac{\partial \rho_{k}}{\partial t}+\operatorname{div} \rho_{k} \boldsymbol{v}_{k}=\sum_{j=1}^{r} \nu_{k j} J_{j}, \\
& (k=1,2, \cdots, n) \\
& \frac{\partial \rho}{\partial t}+\operatorname{div} \rho \boldsymbol{v}=0 \quad\left(\rho=\sum_{k=1}^{n} \rho_{k}\right) \\
& \frac{\partial \rho e}{\partial t}+\operatorname{div}\left(\rho e \boldsymbol{v}+\boldsymbol{F}_{q}\right) \\
& =-P: \operatorname{Grad} \boldsymbol{v}+\sum_{k=1}^{n} \boldsymbol{F}_{k} \cdot f_{k} \\
& T \frac{d s}{d t}=\frac{d e}{\partial t}+p \frac{d \alpha}{d t}-\sum_{k=1}^{n} \mu_{k} \frac{d c_{k}}{d t}
\end{aligned}
$$

Strictly, (A3) is based on the assumption that the Gibbs relation

$$
T d s=d e+p d \alpha-\sum_{k=1}^{n} \mu_{k} d c_{k}
$$

remains valid for a mass element followed along its center of gravity motion, where $e$ is the specific internal energy, $\alpha$ the specific volume, $\boldsymbol{F}_{q}$ the heat flux $\left(=\boldsymbol{F}_{H}+\boldsymbol{F}_{s}+\boldsymbol{F}_{l}\right), c_{k}$ the mass fraction $\left(=\rho_{k} / \rho\right)$ and the other notations are listed in Section 2. We can obtain (2) by eliminating $d e / d t$ and $d c_{k} / d t$ from (A3) with the use of (A1) and (A2) (see de Groot and Mazur (1969) for the details.)

If we want to find an explicit expression of the latent heating in the total differential of the entropy (Iribarne and Godson, 1973), we may start with

$$
\begin{aligned}
d s= & \left(\frac{\partial s}{\partial T}\right)_{p, c_{k}} d T+\left(\frac{\partial s}{\partial p}\right)_{T, c_{k}} d p \\
& +\sum_{k} \frac{\partial s}{\partial c_{k}} d c_{k} .
\end{aligned}
$$

Remembering the thermodynamical relations:

$$
\begin{aligned}
& \left(\frac{\partial s_{k}}{\partial T}\right)_{p_{k}, c_{k}}=C_{p k} / T \\
& \left(\frac{\partial s_{k}}{\partial p_{k}}\right)_{T, c_{k}}=-\left(\frac{\partial \alpha_{k}}{\partial T}\right)_{p_{k}, c_{k}} \\
& = \begin{cases}-R_{k} / p_{k} & \text { for the gas phase } \\
-\alpha_{k} \beta_{k} \approx 0 & \text { for the liquid or solid }\end{cases}
\end{aligned}
$$

and that $s=\sum_{k} c_{k} s k$ and $p=\sum_{k} p_{k}$, we can write (A5) in the form

$$
d s=C_{p} d(\ln T)-\sum_{k}^{\prime} c_{k} R_{k} d\left(\ln p_{k}\right)+\sum_{k} s_{k} d c_{k}
$$

where $\sum_{k}^{\prime}$ denotes the summation over the gas components only, $C_{p}\left(=\sum_{k} c_{k} C_{p k}\right)$ is the specific heat capacity at constant pressure, $R$ the gas constant, and $\beta$ the isobaric expansion coefficient. Taking into account that $d c_{i}+d c_{w}+d c_{v}$ $=0$, we introduce the latent heats

$$
l_{v}=T\left(s_{v}-s_{i}\right), \quad l_{w}=T\left(s_{w}-s_{i}\right),
$$

where the suffixes $i, w$ and $v$ denote ice, liquid water and water vapor, respectively. We thus obtain

$$
\begin{aligned}
d s= & C_{p} d(\ln T)-\sum_{k}^{\prime} c_{k} R_{k} d\left(\ln p_{k}\right) \\
& +\left(l_{v} / T\right) d c_{v}+\left(l_{w} / T\right) d c_{w} .
\end{aligned}
$$

\section{Appendix B}

\section{A gradient method for function minimization}

The problem of finding minima of the entropy exchange rate discussed in the text can be stated in mathematical terms as follows. A given function of $n$ independent variables,

$$
g(\boldsymbol{x})=g\left(x^{1}, x^{2}, \cdots, x^{n}\right),
$$

is to be minimized under the constraint

$$
h(\boldsymbol{x})=h\left(x^{1}, x^{2}, \cdots, x^{n}\right)=0,
$$

within the domain

$$
a^{i} \leqq x^{i} \leqq b^{i}, \quad(i=1,2, \cdots, n)
$$

where $a^{i}$ and $b^{i}$ are constants.

We assume that $g(x)$ and $h(x)$ are differentiable. We follow Schulman's gradient method (Schulman, 1977), which can be divided into two kinds of steps: i) to find a point $\boldsymbol{x}_{M}$ which satisfies (B2) within the domain (B3), and ii) to find a minimizing point in the steepest descent direction of $g$ at $\boldsymbol{x}_{M}$ subject to (B2) within the domain (B3). Both steps are alternatively repeated until a minimum of $g(x)$ is attained.

i) Newton's method

For $n=1$, let $x_{m}$ be the $m$-th approximation 
to (B2). Then the $m$-th correction $\varepsilon_{m}\left(=x_{m+1}\right.$ $\left.-x_{m}\right)$ is given by Newton's method as a solution of

$$
h\left(x_{m}\right)+\frac{d h}{d x}\left(x_{m}\right) \varepsilon_{m}=0 .
$$

Similarly, for $n \geqq 2$, a solution of

$$
h\left(\boldsymbol{x}_{m}\right)+D h\left(\boldsymbol{x}_{m}\right) \cdot \boldsymbol{\varepsilon}_{m}=0
$$

gives the $m$-th correction $\boldsymbol{\varepsilon}_{m}\left(=\boldsymbol{x}_{m+1}-\boldsymbol{x}_{m}\right)$, where $D h\left(x_{m}\right)$ is the derivation of $h$ at $\boldsymbol{x}_{m}$. However, (B5) does not determine $\boldsymbol{\varepsilon}_{m}$ uniquely, because (B5) gives only one relation to $n$ independent variables $\varepsilon_{m}$. Hence, we can assign $n-1$ variables arbitrarily; we take the norm $\varepsilon_{m}=\left|\varepsilon_{m}\right|$ as a dependent variable and assign the cosine $\hat{\varepsilon}_{m}{ }^{i}$ of the angle between $\varepsilon_{m}$ and the $x^{i}$ axis, so that $\hat{\boldsymbol{\varepsilon}}_{m}=\left(\hat{\varepsilon}_{m}{ }^{i}\right)=\boldsymbol{\varepsilon}_{m} / \varepsilon_{m}$. Thus, solving (B5) with respect to $\varepsilon_{m}$, we obtain

$$
\varepsilon_{m}=-\left.\frac{h}{\sum_{i=1}^{n} \frac{\partial h}{\partial x^{i}} \hat{\boldsymbol{\varepsilon}}^{i}}\right|_{\boldsymbol{x}=\boldsymbol{x}_{m}}
$$

In the present study, we take $\hat{\varepsilon}_{m}$ in the direction of $\operatorname{grad} h$, so that

$$
x_{m+1}{ }^{i}=x_{m}^{i}-\left.\frac{h \frac{\partial h}{\partial x^{i}}}{\sum_{j=1}^{n}\left(\frac{\partial h}{\partial x^{j}}\right)^{2}}\right|_{\boldsymbol{x}=\boldsymbol{x}_{m}}
$$

Schulman (1977), on the other hand, took $\hat{\varepsilon}_{m}{ }^{1}=\hat{\varepsilon}_{m}{ }^{2}=\cdots=\hat{\varepsilon}_{m}{ }^{n}=1 / \sqrt{n}$. When $x^{i}{ }_{m+1}$ goes beyond the range (B3), we simply put $x^{i}{ }_{m+1}=$ $a^{i}$ or $b^{i}$.

If $h(x)$ is twice differentiable, we can get an iteration point with better convergence from

$$
h\left(\boldsymbol{x}_{m}\right)+D h\left(\boldsymbol{x}_{m}\right) \cdot \boldsymbol{\varepsilon}_{m}+\frac{1}{2} D^{2} h\left(\boldsymbol{x}_{m}\right) \cdot\left(\boldsymbol{\varepsilon}_{m}, \boldsymbol{\varepsilon}_{m}\right)=0
$$

by extending Hitotumatu's method for $n=1$ (Hitotumatu, 1962). This yields

$$
\varepsilon_{m}= \begin{cases}-2 h /(E+\sqrt{F}) & \text { for } F>0 \text { and } E \geqq 0 \\ -2 h /(E-\sqrt{F}) & \text { for } F>0 \text { and } E<0 \\ -E / G & \text { for } F \leqq 0\end{cases}
$$

where $F=E^{2}-2 h G$ with

$$
\begin{aligned}
E & =D h\left(\boldsymbol{x}_{m}\right) \cdot \hat{\boldsymbol{\varepsilon}}_{m}=\left.\sum_{k=1}^{n} \frac{\partial h}{\partial x^{k}} \hat{\boldsymbol{\varepsilon}}_{m}{ }^{k}\right|_{\boldsymbol{x}=\boldsymbol{x}_{m}} \\
\boldsymbol{G} & =D^{2} h\left(\boldsymbol{x}_{m}\right) \cdot\left(\hat{\boldsymbol{\varepsilon}}_{m}, \hat{\boldsymbol{\varepsilon}}_{m}\right) \\
& =\left.\sum_{j=1}^{n} \sum_{k=1}^{n} \frac{\partial^{2} h}{\partial x^{k} \partial x^{j}} \hat{\boldsymbol{\varepsilon}}_{m}{ }^{k} \hat{\boldsymbol{\varepsilon}}_{m}^{j}\right|_{\boldsymbol{x}=\boldsymbol{x}_{m}}
\end{aligned}
$$

The extension of (B5) to (B8) is necessary when $D h\left(x_{m}\right)$ vanishes. However, such a case is hardly expected for the boundary condition (7). Moreover, we must approximate the derivatives of $h$ and $g$ by finite defferencing so that higher derivatives are not desirable to save computation time. We therefore use (B7) in the present study.

\section{ii) The direction for minimization}

We derive here the direction of minimization found by Schulman (1977) from a geometrical consideration.

Let $x_{M}$ be the $M$-th iteration point to find a minimum. The direction of the steepest descent of $g$ is the direction of $-\operatorname{grad} g$. On the other hand, any point that satisfies (B2) in the neighborhood of $x_{M}$ is located close to the tangential plane of $h$ at $x_{M}$, that is, the plane perpendicular to $\operatorname{grad} h$ at $\boldsymbol{x}_{M}$. Therefore, we should find $\boldsymbol{x}_{M+1}$ in the projected direction of $-\operatorname{grad} g$ on the tangential plane:

$$
-\left(\operatorname{grad} g-\left\langle\operatorname{grad} g, \frac{\operatorname{grad} h}{|\operatorname{grad} h|}\right\rangle \frac{\operatorname{grad} h}{|\operatorname{grad} h|}\right)
$$

where $\langle$,$\rangle denotes the inner product. The i$-th component of (B12) is written as

$$
-\frac{\partial g}{\partial x^{i}}+\frac{\sum_{j=1}^{n} \frac{\partial g}{\partial x^{j}} \frac{\partial h}{\partial x^{j}}}{\sum_{k=1}^{n}\left(\frac{\partial h}{\partial x^{k}}\right)^{2}} \frac{\partial h}{\partial x^{i}}
$$

which agrees with the direction obtained by Schulman; however, the sign of (B13) is reversed because we are considering minima of a function.

\section{References}

Budyko, M. I., 1969: The effect of solar radiation variations on the climate of the Earth. Tellus, 21, 611-619.

- 1978: Energy factors of the global water cycle in nature, in World water balance and water resources of the earth, the Unesco Press, Paris, pp. 57-62.

de Groot, S. R. and P. Mazur, 1969: Non-equilibrium thermodynamics. North-Holland Publ. Co., Amsterdam.

Dopplick, T. G., 1979: Radiative heating of the global atmosphere: corrigendum. J. Atmos. Sci., 36, 1812-1817.

Dutton, J. A., 1973: The global thermodynamics of atmospheric motion. Tellus, 25, 89-110.

Golitsyn, G. S. and I. I. Mokhov, 1978: Stability and extremal properties of climate models. Izves- 
tiya, Atm. Oc. Phys., 14, 271-277.

Grassl, H., 1981: The climate at maximum entropy production by meridional atmospheric and oceanic heat fluxes. Quart. J.R. Met. Soc., 107, 153-166.

Hitotumatu, S., 1962: Proceedings of the 3rd Programming Symposium, pp. B-29-36, cited in Numerical Analysis II, Foundations of Technology 4, (in Japanese), 1968, Iwanami, Tokyo, 179-181.

Hunt, G. E. and S. R. Mattingly, 1976: Infrared radiative transfer in planetary atmospheres-I. Effects of computational and spectroscopic economies on thermal heating/cooling rates. $J$. Quant. Spectrosc. Radiat. Transfer, 16, 505-520.

Iribarne, J. V. and W. L. Godson, 1973: Atmospheric Thermodynamics, D. Reidel Publ. Co., Dordrecht.

Katayama, A., 1966: On the radiation budget of the troposphere over the northern hemisphere (I). J. Meteor. Soc. Japan, 44, 381-401.

- 1974: A simplified scheme for computing radiative transfer in the troposphere. Tec. Rep. No. 6, Dept. Met. UCLA, 77 pp.

Lacis, A. A. and J. E. Hansen, 1974: A parameterization for the absorption of solar radiation in the earth's atmosphere. J. Atmos. Sci., 31, 118133.

Lorenz, E. N., 1955: Available potential energy and the maintenance of the general circulation. Tellus, 7, 157-167.

, 1960: Generation of available potential energy and the intensity of the general circulation. Dynamics of Climate, R. L. Pfeffer, Ed., Pergamon Press, 86-92.

Manabe, S. and R. T. Wetherald, 1967: Thermal equilibrium of the atmosphere with a given distribution of relative humidity. J. Atmos. Sci., 24, 241-259.

Mobbs, S. D., 1982: Extremal principles for global climate models. Quart. J.R. Met. Soc., 108, 535-550.

Newell, R. E., J. W. Kidson, D. G. Vincent and G. J. Boer, 1974: The General Circulation of the Tropical Atmosphere and Interactions with Extratropical Latitudes, Volume 2. The MIT Press, $371 \mathrm{pp}$.

Nicolis, G. and I. Prigogine, 1977: Self-Organization in Nonequilibrium Systems-From Dissipative Structure to Order through Fluctuations, John Wiley and Sons, Inc., New York. and C. Nicolis, 1980: On the entropy balance of the earth-atmosphere system. Quart. J. R. Met. Soc., 106, 691-706.

Oort, A. H. and E. M. Rasmusson, 1971: Atmospheric Circulation Statistics. NOAA Prof. Pap. No. 5, 323 pp.

Paltridge, G. W., 1975: Global dynamics and climate -a system of minimum entropy exchange. Quart. J. R. Met. Soc., 101, 475-484.

, 1978: The steady-state format of global climate. Quart. J. R. Met. Soc., 104, 927-945. , 1979: Climate and thermodynamic systems of maximum dissipation. Nature, 279, 14 June issue, 630-631.

- 1981: Thermodynamic dissipation and the global climate system. Quart. J. R. Met. Soc., 107, 531-547.

Prigogine, I., 1967: Introduction to Thermodynamics of Irreversible Processes, Third edition. Interscience Publishers, a division of John Wiley and Sons, New York.

Roberts, R. E., J. E. A. Selby and L. M. Biberman, 1976: Infrared continuum absorption by atmospheric water vapor in the 8-12 $\mu \mathrm{m}$ window. Appl. Opt., 15, 2085-2090.

Rodgers, C. D., 1976: Comments on Paltridge's 'minimum entropy exchange' principle. Quart. J. R. Met. Soc., 102, 455-457.

Sawada, Y., 1981: A thermodynamic variational principle in nonlinear non-equilibrium phenomena. Prog. Theor. Phys., 66, 68-76.

Schulman, L. L., 1977: A theoretical study of the efficiency of the general circulation. J. Atmos. Sci., 34, 559-580.

Sellers, W. D., 1965: Physical Climatology, University of Chicago Press, Chicago, Ill., and London.

_ 1969: A global climatic model based on the energy balance of the earth-atmosphere system. J. Appl. Met., 8, 392-400.

Smithsonian Meteorological Tables, 1966: Table 133, Total annual and seasonal solar radiation at the top of the atmosphere, Sixth revised edition prepared by R. J. List, The Smithsonian Institution, Washington.

Somerville, R. C., P. H. Stone, M. Halem, J. E. Hansen, J. S. Hogan, L. M. Druyan, G. Russell, A. A. Lacis, W. J. Quirk and J. Tenenbaum, 1974: The GISS model of the global atmosphere. J. Atmos. Sci., 31, 84-117. 


\section{エントロピー交換率極小の気候}

\section{野 田彰・時 岡 達 志 気象研究所}

放射加熱を含んだエントロピー釣り合いの式を導き，Paltridge が提唱しているエントロピー交換率最小の原 理の検証を試みた。エントロピー釣り合いのモデルでは, 影熱・潜熱輸送に伴う熱力学的散逸（エントロピー生 成）が，運動エネルギーの摩擦による散逸に対して無視出来ない。

エントロピー交換率極小の気候を探すために, 南北方向に 2 及び10の緯度帯に分割した緯度平均 2 次元モデル を用いた。放射加熱計算は，大気を10層に分割して行い，雲は，そのうち 3 層に出現すると仮定した。水蒸気分 布として，絶対湿度分布を与えた場合と，相対湿度分布を与えた場合について，極小解を探した。その結果，前 者について，極小解が複数個見つかったが，後者については，見い出せなかった。前者の場合，現在の気候に似 た気温・雲量分布を持つ気候が，極小解の一つとして得られたが，最小解ではなかっだ。結論として，エントロ ピー交換率最小の気候は，水蒸気分布のパラメタリゼーションに，敏感に依存することが示された。 